\title{
Hypoxic stress increases NF-KB and iNOS mRNA expression in normal, but not in keratoconus corneal fibroblasts
}

\author{
Tanja Stachon ${ }^{1,2}$ (D) - Lorenz Latta ${ }^{2}$ • Berthold Seitz ${ }^{1}$ • Nóra Szentmáry ${ }^{2,3}$
}

Received: 4 March 2020 / Revised: 30 July 2020 / Accepted: 16 August 2020 / Published online: 4 September 2020

(C) The Author(s) 2020

\begin{abstract}
Background Keratoconus (KC) is associated with oxidative stress and hypoxia and as several times discussed, potentially with inflammatory components. Inflammation, hypoxia, and oxidative stress may result in metabolic dysfunction and are directly linked to each other. In the current study, we investigate the effect of hypoxia through NF- $\mathrm{B}$ signaling pathways on iNOS, hypoxia-induced factors (HIF), ROS, and proliferation of normal and KC human corneal fibroblasts (HCFs), in vitro.

Methods Primary human KC-HCFs and normal HCFs were isolated and cultured in DMEM/Ham's F12 medium supplemented with $5 \%$ fetal calf serum. Hypoxic conditions were generated and quantitative PCR and Western blot analysis were performed to examine NF-KB, iNOS, HIF, and PHD2 expression in KC and normal HCFs. ROS level was analyzed using flow cytometry and proliferation by BrdU-ELISA.

Results Hypoxia increased NF- $\mathrm{kB}$ mRNA and protein expression in normal HCFs, but in KC-HCFs NF- $\mathrm{KB}$ mRNA and protein expression remained unchanged. Hypoxic conditions upregulated iNOS mRNA expression of normal HCFs, but iNOS mRNA expression of KC-HCFs and iNOS protein expression of both HCF types remained unchanged. Hypoxia downregulated HIF- $\alpha$ and HIF-2 $\alpha$ mRNA expression in normal and KC-HCFs. PHD2 mRNA expression is upregulated under hypoxia in KC-HCFs, but not in normal HCFs. PHD2 protein expression was upregulated by hypoxia in both HCF types. Total ROS concentration is downregulated in normal and KC-HCFs under hypoxic conditions. Proliferation rate of KC-HCFs was upregulated through hypoxia, but did not change in normal HCFs.

Conclusions Hypoxia increases NF- $\mathrm{KB}$ and iNOS mRNA expression in normal HCFs, but there does not seem to be enough capacity in KC-HCFs to increase NF-KB and iNOS mRNA expression under hypoxia, maybe due to the preexisting oxidative stress. HIF and PHD2 do not show altered iNOS regulation under hypoxic conditions in KC-HCFs, and therefore do not seem to play a role in keratoconus pathogenesis. An increased proliferation of cells may refer to compensatory mechanisms under hypoxia in $\mathrm{KC}$. Understanding the mechanism of the altered regulation of NF- $\mathrm{KB}$ and iNOS in KC-HCFs will provide better insight into the potential inflammatory component of the $\mathrm{KC}$ pathogenesis.
\end{abstract}

Keywords Keratoconus $\cdot$ Hypoxia $\cdot \mathrm{NF}-\mathrm{kB} \cdot \mathrm{iNOS} \cdot \mathrm{HIF} \cdot \mathrm{PHD} 2 \cdot$ Inflammation $\cdot$ Pathogenesis

Tanja Stachon

tanja.stachon@uks.eu

1 Department of Ophthalmology, Saarland University Medical Center, Homburg, Saar, Germany

2 Dr. Rolf. M. Schwiete Center for Limbal Stem Cell and Aniridia Research, Saarland University, Homburg/Saar, Germany

3 Department of Ophthalmology, Semmelweis University, Budapest, Hungary

\section{Background}

Keratoconus $(\mathrm{KC})$ is a progressive corneal disease characterized by thinning and deformation, but with unknown etiology. So far, KC has been characterized as a non-inflammatory corneal disease, but several studies suggest an inflammatory component in its development [1, 2]. Karamichos et al. suggested the involvement of altered metabolic pathways in its pathogenesis, but it has also been described that oxidative stress plays a role [3-5].

It is known that reactive oxidative species (ROS) are elevated in $\mathrm{KC}$ corneas [5]. The reason could be, among others, altered metabolic pathways or hypoxic conditions due to 


\section{Key messages}

- Keratoconus has been characterized as a non-inflammatory corneal disease, but several studies suggest an inflammatory component in its development.

- Hypoxia increases NF-kB and iNOS mRNA expression in normal human corneal fibroblasts (HCFs), but there does not seem to be enough capacity in keratoconus human corneal fibroblasts (KC-HCFs) to increase NF- $\mathrm{BB}$ and iNOS mRNA expression under hypoxia, maybe due to the preexisting oxidative stress.

- HIF and PHD2 do not show altered iNOS regulation under hypoxic conditions in KC-HCFs, and therefore do not seem to play a role in keratoconus pathogenesis.

mitochondrial dysfunction of mtDNA-mediated inflammation. If a hypoxic state is present due to altered metabolic functions, these also have an influence on the oxidative state and can act as a pro-inflammatory mediator. Both hypoxic conditions and oxidative stress trigger an inflammatory cell response [6].

In our previous study, we determined an increased inducible nitric oxide synthase (iNOS) and nuclear factor kappa B (NF-kB) mRNA expression in KC-HCFs compared with normal cells [7]. This was accompanied by an increased NF- $\mathrm{KB}$ protein expression, without a change in iNOS protein levels.

iNOS converts L-arginine into nitric oxide (NO), which reacts as a free radical and is also part of the ROS/RNS state in the cells. The induction of iNOS is mainly mediated by inflammatory cytokines such as IL-1, TNF- $\alpha$, and IFN- $\gamma$, but also by lipopolysaccharides (LPS) in macrophages via NF-kB (Fig. 1).
However, several cell types constitutively express iNOS without an inflammatory process [8]. It is also known that ROS production by $\mathrm{KC}-\mathrm{HCFs}$ is higher than that in $\mathrm{HCF}$.

The hypoxia-inducible factor $\alpha(\mathrm{HIF} \alpha)$ acts as an oxygen sensor in the cellular response to reduced oxygen supply [9]. Its main subunits are HIF- $1 \alpha$ and HIF- $2 \alpha$. Under hypoxic conditions, HIF $\alpha$ is stabilized by prolyl-hydroxylases (PHDs) and translocated into the cell nucleus. Then, the $\alpha$ subunit forms a complex with $\operatorname{HIF} \beta$ and acts as a transcription factor in the hypoxic reaction, e.g., for iNOS (Fig. 2).

In keratoconus, cell density is reduced in all layers of the cornea [10]. However, hypoxia can induce proliferation of many cell types and is known as a regulatory factor [11]. All factors, ROS/RNS and oxygen homeostasis via HIF- $1 \alpha$ and PHDs and proliferation, are involved in the interaction of inflammation and altered metabolic balance and influence each other.
Fig. 1 Activation of iNOS transcription through NF-kB binding at the iNOS promotor region. The scheme displays the activation of NF- $\mathrm{kB}$ by IFN- $\gamma$, LPS, TNF- $\alpha$, or IL- $1 \beta$. NF-KB can directly bind to the iNOS promotor region to activate the transcription of iNOS which is able to start the production of nitric oxide

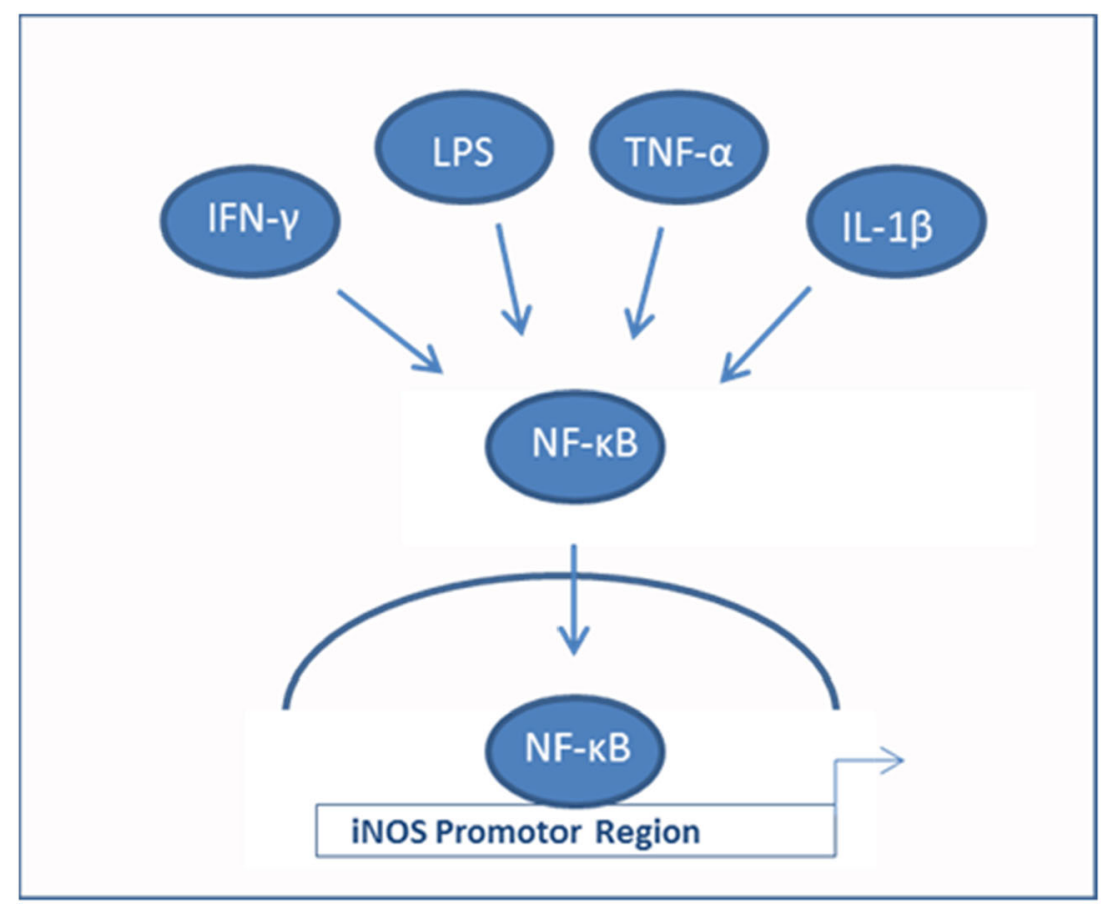






Fig. 2 Under normoxia, HIF- $\alpha$ is hydroxylated by PHDs, which target HIF- $\alpha$ for von Hippel - Lindau protein degradation. Under hypoxic conditions, through inflammation or oxidative stress, HIF- $\alpha$ transcription is

In this study, we investigated the regulation of NF- $\mathrm{KB}$, iNOS, HIF- $1 \alpha$, HIF- $2 \alpha$, and PHD expression; ROS, and proliferation under hypoxic conditions in keratoconus corneal fibroblasts compared with normal control cells, in vitro.

\section{Methods}

\section{Cell culture}

Eight normal human corneas were obtained from the LIONS Cornea Bank Saar-Lor-Lux, Trier/Westpfalz, and 8 corneas from $\mathrm{KC}$ patients were obtained from elective penetrating keratoplasties. For the keratoconus corneas, all eyes with previous ocular surgery have been excluded. Donor corneas, which did not match the criteria for transplantation (less than 2000 endothelial cells $/ \mathrm{mm}^{2}$ ), have been used for the experiments.

To isolate keratocytes, human corneoscleral/corneal buttons were first rinsed in PBS (Merck Sigma-Aldrich Chemie GmbH, Taufkirchen, Deutschland). The central corneal button was cut into small pieces and was incubated in culture medium with $1.0 \mathrm{mg} / \mathrm{ml}$ collagenase A (Roche Diagnostic GmbH, Mannheim, Germany, No. 10103578001) for $24 \mathrm{~h}$ at $37^{\circ} \mathrm{C}$. The digested tissue and cells were centrifuged at $800 \mathrm{~g}$ for $7 \mathrm{~min}$ and resuspended in culture medium, which consisted of basic medium (DMEM/F12, Sigma-Aldrich ${ }^{\circledR} \mathrm{GmbH}$, Geisenheim, Germany, No. 11594426) supplemented by 5\% fetal calf serum (FCS) (Fisher Scientific GmbH, Schwerte, Germany, No. 11573397). The cell suspension was seeded induced via NF- $\mathrm{K}$ dependent mechanism. HIF- $\alpha$ is located in the cell nucleus and binds to the $\beta$ unit and serves as a transcription factor, e.g. for iNOS.

in $75-\mathrm{cm}^{2}$ culture flasks, using DMEM/F12 (+5\% FCS). Thereafter, medium was changed every 2 to 3 days until cells reached confluence. As keratocytes were cultured with FCS, we specify them further on in the manuscript as "human corneal fibroblasts" (HCF) or "keratoconus human corneal fibroblast" (KC-HCF) [12].

The cell passages 3 to 8 were used for the experiments.

Hypoxic conditions were generated using $150 \mu \mathrm{M} \mathrm{CoCl}_{2}$ (PHD inhibitor, Sigma-Aldrich ${ }^{\circledR} \mathrm{GmbH}$, Geisenheim, Germany, No. 60818) for $4 \mathrm{~h}, 24 \mathrm{~h}$, and $48 \mathrm{~h}$, to evaluate the time-point with changes in NF- $\mathrm{kB}$, iNOS, HIF-1 $\alpha$, and HIF- $2 \alpha$ mRNA and protein expression. Since $\mathrm{CoCl}_{2}$ is an inhibitor of prolyl-hydroxylases, which induce a chemical hypoxia, we used $1 \% \mathrm{O}_{2}$ atmosphere in a hypoxic chamber (Modular Incubator Chamber, Billups-Rothenberg, Inc., CA, USA) to examine the effect of hypoxia on prolyl-hydroxylase 2 [13]. For PHD2 analysis, we generated $1 \% \mathrm{O}_{2}$ for $48 \mathrm{~h}$ for PHD2 mRNA and protein expression measurements. Shortly, the cell culture flask was placed in a hypoxic chamber; the chamber was connected to a gas mixture $\left(1 \% \mathrm{O}_{2}, 5 \% \mathrm{Co}_{2}\right.$, $94 \% \mathrm{~N}_{2}$ ) and was filled with the gas for $2 \mathrm{~min}$. This procedure was repeated after $24 \mathrm{~h}$. The chamber including the cell culture flasks was incubated at $37^{\circ} \mathrm{C}$ in the cell culture incubator.

\section{RNA isolation and CDNA synthesis}

Human normal and KC-HCFs were seeded in $75-\mathrm{cm}^{2}$ cell culture flasks. After reaching confluence, the cells were harvested using Trypsin-EDTA (0.05\% trypsin/0.02\% EDTA, 
Table 1 Primer pairs for $\mathrm{qPCR}$

\begin{tabular}{lllr}
\hline Targeted cDNA & Gene symbol & $5^{\prime}$ forward primer 3' or Qiagen Cat. No. & Amplicon size bp \\
\hline NF-kB & RELA & QT02324308 & 136 \\
iNOS & NOS2 & CTGGCAAGCCCAAGGTCTAT & 517 \\
$\quad$ Forward 5' $\rightarrow 3^{\prime}$ & & GGAGGCTCCGATCAATCCAG & \\
Reverse 5' $\rightarrow 3^{\prime}$ & HIF1A & QT00083664 & 104 \\
HIF-1 $\alpha$ & EPAS1 & QT00069587 & 127 \\
HIF-2 $\alpha$ & EGLN1 & QT00222684 & 123 \\
HIF-PHD2 & P4HTM & QT00041048 & 87 \\
P4H-TM & TBP & QT00000721 & 132 \\
TBP & & & \\
\hline
\end{tabular}

Sigma-Aldrich® GmbH, Geisenheim, Germany). The RNA isolation was performed according to the manufacturer's protocol (ISOLATE II RNA/DNA/Protein Kit, Luckenwalde, Germany) and RNA was stored at $-80^{\circ} \mathrm{C}$ until cDNA synthesis (One Taq® RT-PCR Kit, New England Biolabs INC, Frankfurt, Germany). For cDNA, $1 \mu \mathrm{g}$ of total RNA was used as template for all samples. The cDNA was stored at $-20^{\circ} \mathrm{C}$ until further use.

\section{Quantitative PCR}

For quantitative PCR (qPCR), Tata-binding protein (TBP), NF- $\kappa$ B (RELA/NF- B p65), HIF-1 $\alpha$, HIF-2 $\alpha$, and PHD2 validated primer sets for use in SYBR Green-based quantitative PCR, obtained from Qiagen GmbH (Hilden, Germany), were utilized. For iNOS, primers were synthesized by MWG Eurofins (Table 1).

The qPCR experiment was carried out for all KC samples and for controls in 96-well plates using AceQ SYBR qPCR Master Mix (Vazyme Biotech, China) and a PCR Thermocycler QuantStudio 5 Real-Time PCR System (ThermoFisher Scientific ${ }^{\mathrm{TM}} \mathrm{GmbH}$, Dreieich, Germany).

The relative normalized expression of NF- $\kappa \mathrm{B}$, iNOS, HIF$1 \alpha, \mathrm{HIF}-2 \alpha$, and PHD2 was compared with the respective TBP reference gene. The $\Delta \Delta$ cycle threshold (Ct) fold change was quantified by comparing the $\mathrm{Ct}$ obtained from the unknown samples compared with the $\mathrm{Ct}$ of the reference gene TBP. For qPCR, the amplification conditions were $95^{\circ} \mathrm{C}$ for $10 \mathrm{~s}, 64^{\circ} \mathrm{C}$ for $10 \mathrm{~s}$, and $72^{\circ} \mathrm{C}$ for $45 \mathrm{~s}$ and 40 cycles.

\section{Western blot analysis}

To determine NF- $\kappa$ B, iNOS, HIF- $1 \alpha$, HIF- $2 \alpha$, and PHD2 protein expression in corneal fibroblasts, $20 \mu \mathrm{g}$ protein of normal or KC human corneal fibroblasts, obtained with ISOLATE II RNA/DNA/Protein Kit (Luckenwalde, Germany), was used (Western blot analysis). Antibodies against NF-кB p65, HIF-1 $\alpha$, HIF- $2 \alpha$, and PHD2 were purchased from Cell Signaling Technology (Frankfurt am Main,
Germany), and anti-iNOS antibody from Abcam (Cambridge, UK). After boiling the samples for $5 \mathrm{~min}$ at $95{ }^{\circ} \mathrm{C}$, proteins were separated using NuPAGE TM bis-tris precast $4-12 \%$ bistris gels (ThermoFisher Scientific ${ }^{\mathrm{TM}} \mathrm{GmbH}$, Dreieich, Germany). Following protein separation, the proteins were transferred onto a nitrocellulose membrane with the Trans Blot Turbo Transfer System (BioRad, Hercules, CA, USA). Primary antibodies were diluted in WesternFroxx anti-rabbit HRP solution containing blocking reagent and secondary antibody (BioFroxx GmbH, Einhausen, Germany). For loading control, blots were stripped in stripping buffer (BioFroxx), and reprobed with calnexin antibody (Enzo Life Sciences Ag, Lausen, Switzerland, No. ADI-SPA-865). Visualization was performed using an imaging system (LAS 4000 system, Fujifilm).

\section{Protein measurement}

For Western blot analysis, protein quantity was determined according to Bradford's method, using bovine serum albumin as a standard. The absorbance was measured at $595 \mathrm{~nm}$ and the concentrations were quantified.

\section{ROS detection}

To evaluate total ROS concentration in keratocytes, the Total ROS assay kit for flow cytometry was used (Thermo Fisher Scientific, Karlsruhe, Germany). Shortly, cells were seeded into 6-well plates and were cultivated until $90 \%$ confluence. One hundred fifty micrometers micromolar $(150 \mu \mathrm{M})$ of the hypoxia-mimicking agent $\mathrm{CoCl}_{2}$ was used to generate hypoxic conditions for $48 \mathrm{~h}$. Thereafter, cells were harvested and stained with ROS assay stain for $60 \mathrm{~min}$ at $37^{\circ} \mathrm{C}$. FACS analysis was performed using FACS Canto (Becton Dickinson, Heidelberg, Germany) of the 488 nm FITC channel. Ten thousand events were acquired for each analysis. Geometric mean of fluorescence intensity was evaluated using WinMDI 2.9. 


\section{BrdU assay}

Proliferation of HCFs was assessed after culturing the cells under hypoxic conditions using $150 \mu \mathrm{M} \mathrm{CoCl}_{2}$ with the proliferation ELISA-BrdU kit, by the measurement of BrdU (5bromo-2'deoxyuridine) incorporation in the newly synthesized cellular DNA. HCFs were seeded in a 96-multiwell plate at a density of $6 \times 10^{3}$ cells $/ \mathrm{cm}^{2}$ in $100 \mu l$ culture medium per well. After a growth period of $24 \mathrm{~h}$, the culture medium was changed to a $\mathrm{CoCl}_{2}$ containing culture medium, at $37^{\circ} \mathrm{C}$ for $48 \mathrm{~h}$. The test was performed according to the manufacturer's protocol (Cell Proliferation ELISA, BrdU colorimetric, Roche, No 11647229001, Sigma-Aldrich ® GmbH, Geisenheim, Germany).

\section{Statistical analysis}

For statistical analysis, the GraphPad Prism 7.04 was used. Statistical analysis was performed using the Mann-Whitney $U$ test for comparison between groups. $p$ values below 0.05 were considered statistically significant.

\section{Results}

\section{NF-kB, iNOS, HIF-1 $a$, HIF-2 $a$, and PHD2 mRNA expression and Western blot analysis under normoxic and hypoxic conditions}

mRNA and Western blot measurements were performed following hypoxic conditions for 4,24 , and $48 \mathrm{~h}$. Below we summarize results for the time-points with changes in
mRNA and protein expression, which is also summarized at Table 2. For the other time-points, without changes in mRNA and protein expression, compared with controls (under hypoxic conditions) data are not shown below or at Table 2 .

Figure 3 displays NF-кB, iNOS, HIF-1 $\alpha$, HIF- $2 \alpha$, and PHD2 mRNA and protein expression under normoxic and hypoxic conditions. NF- $\mathrm{kB}$ mRNA is displayed after $4 \mathrm{~h}$ and iNOS, HIF- $1 \alpha$, HIF- $2 \alpha$, and PHD2 mRNA after 48 h of hypoxic conditions. Hypoxic conditions for Western blot analysis of NF-kB iNOS, HIF- $1 \alpha$, HIF- $2 \alpha$, and PHD2 were 48 h.

In KC-HCFs, NF-KB mRNA $(p=0.0098)$ and protein $(p=$ 0.0012 ) expression was increased compared with normal HCFs, under normoxic conditions. Through hypoxia for $4 \mathrm{~h}$, NF- $\kappa \mathbf{B}$ mRNA expression increased in normal HCFs $(p=$ 0.0089 ), but NF- $\mathbf{k B}$ mRNA expression in KC-HCFs and $\mathbf{N F}-\boldsymbol{k B}$ protein expression in normal and $\mathrm{KC}-\mathrm{HCFs}$ remained unchanged $(p>0.721)$.

iNOS mRNA expression was significantly higher in KCHCFs than in normal HCFs $(p<0.0001)$ under normoxic conditions, but iNOS protein expression did not differ between both HCF types $(p=0.841)$. Hypoxic conditions for $48 \mathrm{~h}$ significantly increased iNOS mRNA expression of normal HCFs $(p=0.044)$, but iNOS mRNA expression of KC-HCFs and iNOS protein expression of both HCF types did not change significantly through hypoxia $(p>0.421)$, compared with controls.

HIF-1 $\alpha$ and HIF-2 $\alpha$ mRNA and protein expression did not differ between both HCF types, under normoxic conditions $(p>0.469)$. Following hypoxic conditions for $48 \mathrm{~h}$, HIF-1 $\alpha$ and HIF-2 $\alpha$ mRNA expression was decreased in normal ( $p=0.014$ for both) and KC-HCFs $(p<0.0001$ for both), compared with controls, but HIF-1 $\alpha$ and HIF-2 $\alpha$ protein expression remained unchanged $(p>0.393)$.

Table 2 Comparison of NF-kB, iNOS, HIF-1 $\alpha$, HIF-2 $\alpha$, PHD2 mRNA, and protein expression and total ROS concentration under normoxic and hypoxic conditions in normal HCFs and in KC-HCFs (Mann-Whitney $U$ test). NF-kB mRNA is displayed after $4 \mathrm{~h}$; iNOS,

HIF- $1 \alpha$, and HIF- $2 \alpha$ after 48 h; and PHD2 mRNA after $4 \mathrm{~h}$ and $48 \mathrm{~h}$ of hypoxic conditions. Hypoxic conditions for Western blot analysis of NF-kB iNOS, HIF- $1 \alpha$, HIF- $2 \alpha$, and PHD2 were 48 h $(* p<0.05$; $* * p<0.01 ; * * * p<0.001)$

\begin{tabular}{|c|c|c|c|}
\hline \multirow[t]{2}{*}{ Parameters } & \multirow{2}{*}{$\begin{array}{l}\text { Normoxic conditions } \\
\text { Controls (HCFs) vs KC-HCFs }\end{array}$} & \multicolumn{2}{|c|}{ Normoxic vs hypoxic conditions (48 h) } \\
\hline & & Normal HCFs & $\mathrm{KC}-\mathrm{HCFs}$ \\
\hline NF- $k B$ mRNA expression & Increased in $\mathrm{KC}-\mathrm{HCF} \mathrm{s}^{* * 7}$ & Increased $* *$ & Unchanged \\
\hline $\mathrm{NF}-\mathrm{KB}$ protein expression & Increased in $\mathrm{KC}-\mathrm{HCF} \mathrm{s}^{*} *^{7}$ & Unchanged & Unchanged \\
\hline iNOS mRNA expression & Increased in $\mathrm{KC}-H C F \mathrm{~S}^{* * * 7}$ & Increased $^{*}$ & Unchanged \\
\hline iNOS protein expression & Unchanged & Unchanged & Unchanged \\
\hline HIF- $1 \alpha$ and HIF- $2 \alpha$ mRNA expression & Unchanged & Decreased $*$ & Decreased *** \\
\hline HIF- $1 \alpha$ and HIF- $2 \alpha$ protein expression & Unchanged & Unchanged & Unchanged \\
\hline PHD2 mRNA expression & $\begin{array}{l}\text { Increased in KC-HCFs }(4 h)^{* *} \\
\text { Unchanged }(48 \mathrm{~h})\end{array}$ & $\begin{array}{l}\text { Increased }(4 h)^{*} \\
\text { Unchanged }(48 \mathrm{~h})\end{array}$ & $\begin{array}{l}\text { Decreased }(4 h)^{*} \\
\text { Increased }(48 h)^{* *}\end{array}$ \\
\hline PHD2 protein expression & Unchanged & Increased* & Increased* $^{*}$ \\
\hline Total ROS concentration & Increased in $\mathrm{KC}-\mathrm{CFS} * *$ & Decreased $^{* *}$ & Decreased* \\
\hline Proliferation rate of $\mathrm{HCFs}$ & Decreased in $\mathrm{KC}-H C F{ }^{*}$ & Unchanged & Increased $^{* *}$ \\
\hline
\end{tabular}

No. 7 indicates the literature reference given in the bibliography 
a NF-kB

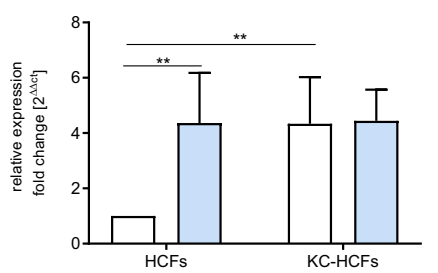

b iNOS

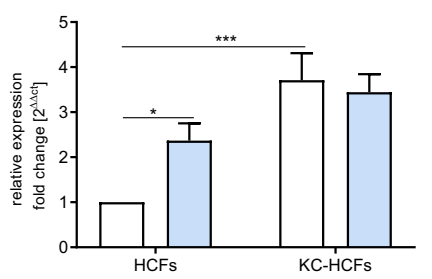

C HIF- $1 \alpha$

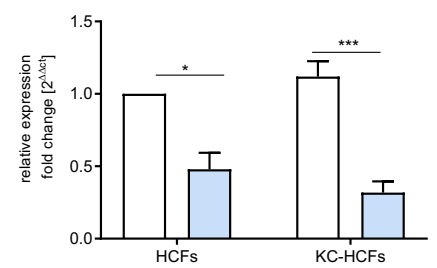

d HIF-2 $\alpha$

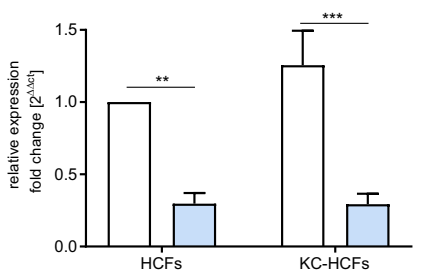

e PHD2



Fig. 3 Effect of hypoxia on NF-kB, iNOS, HIF-1 $\alpha$, HIF-2 $\alpha$, and PHD2 mRNA and protein expression (normoxic conditions: white bars; hypoxic conditions: blue bars). Hypoxic conditions for human corneal fibroblasts (HCFs) and keratoconus human corneal fibroblasts (KC-HCFs) were performed using $150 \mu \mathrm{M} \mathrm{CoCl}_{2}$ for NF-kB (4 h), and iNOS, HIF-1 $\alpha$, and HIF- $2 \alpha(48 \mathrm{~h})$ for PHD2 $1 \% \mathrm{O}_{2}$ atmosphere were generated in a hypoxic chamber for $48 \mathrm{~h}$. Significant differences are indicated. a-e k NF-kB

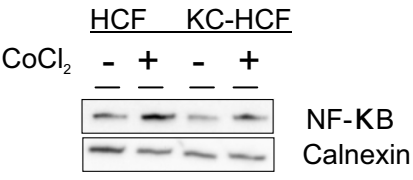

I iNOS
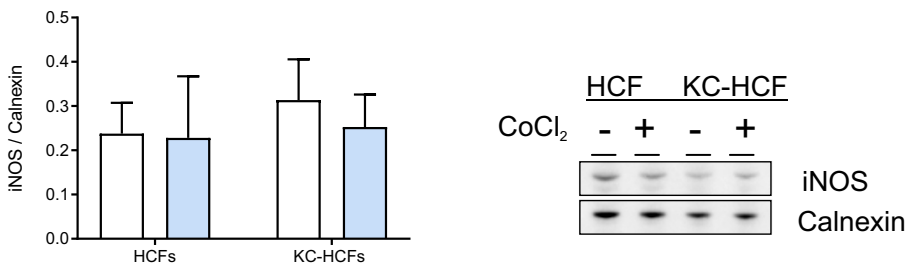

m HIF-1 $\alpha$
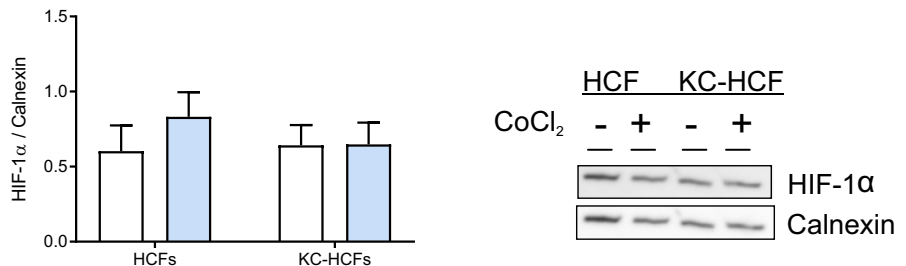

n HIF-2 $\alpha$
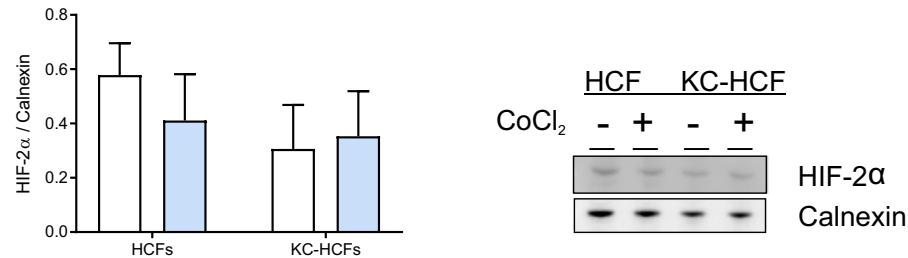

O PHD2

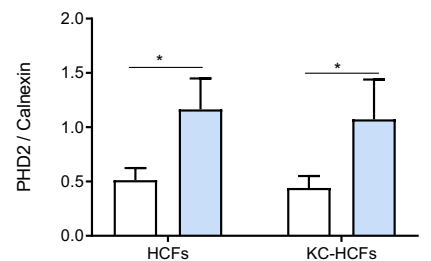

$\mathrm{HCF} \quad \mathrm{KC}-\mathrm{HCF}$

$\mathrm{O}_{2} 20 \% 1 \% 20 \% 1 \%$

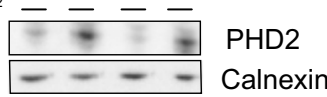

Quantitative mRNA analysis of NF-kB, iNOS, HIF- $1 \alpha$, HIF- $2 \alpha$, and PHD2. Data show mean \pm SEM of at least 8 independent experiments in duplicate. $\mathbf{f}-\mathbf{j}$ Relative quantification of Western blot analysis. Calnexin was used as loading control and to calculate the relative protein expression levels. $\mathbf{k}-\mathbf{0}$ Representative Western blots of NF-KB, iNOS, HIF- $1 \alpha$, HIF- $2 \alpha$, and PHD2 $(* p<0.05 ; * * p<0.01 ; * * *<0.001)$ 
Fig. 4 Total reactive oxygen species (ROS) concentration under normoxic (white bars) and hypoxic conditions (blue bars) using $150 \mu \mathrm{M} \mathrm{CoCl}_{2}$ for $48 \mathrm{~h}$ in normal and KC-HCFs. KC-HCFs show a higher ROS level than control cells. The concentration of ROS is reduced in both cell types following hypoxia. Data were presented as mean \pm SEM of 8 independent experiments. Significant differences are indicated

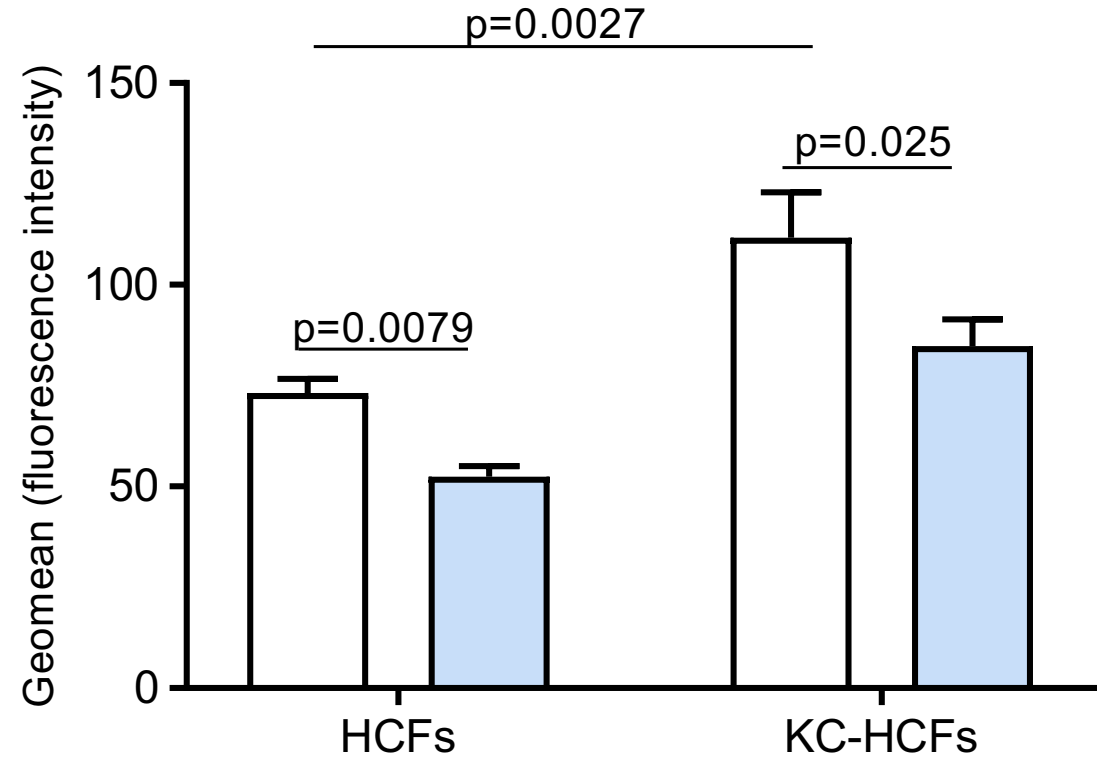

Under normoxic conditions, PHD2 mRNA and protein expression did not differ between normal and KC-HCFs $(p>0.558)$. Under hypoxic conditions for $4 \mathrm{~h}$, PHD2 mRNA expression increased in HCFs $(p=0.0069)$ and decreased in KC-HCFs $(p=0.0046)$ (data not shown at figures). Under hypoxic conditions for $48 \mathrm{~h}$, PHD2 mRNA expression remained unchanged in normals $(p=0.496)$, but increased in KC-HCFs $(p=0.0096)$. PHD2 protein expression increased in both HCF types following $48 \mathrm{~h}$ of hypoxia ( $p=0.031$ for both).

\section{Total ROS concentration in KC and normal HCFs}

Under normoxic conditions, total ROS concentration was significantly higher in KC-HCFs than in normal HCFs $(p=$ 0.0027). Hypoxic conditions for $48 \mathrm{~h}$ resulted in decreased total ROS concentration in normal $(p=0.0079)$ and $\mathrm{KC}$ HCFs $(p=0.025)$, compared with controls (Fig. 4).

\section{Proliferation of KC and normal HCFs}

Under normoxic conditions, proliferation rate in KC-HCFs was lower as in normal HCFs $(p=0.023)$. Through hypoxia for $48 \mathrm{~h}$, proliferation rate of KC-HCFs increased significantly $(p=0.0052)$, but did not change in normal HCFs $(p=0.244)$ (Fig. 5).

\section{Discussion}

The pathogenesis of keratoconus is still unknown, but several changes in the stromal cells of keratoconus patients have
Fig. 5 Proliferation under normoxic (white bars) and hypoxic conditions (blue bars) using $150 \mu \mathrm{M} \mathrm{CoCl}_{2}$ for $48 \mathrm{~h}$ in normal and KC-HCFs. The proliferation rate is reduced in KC-HCFs compared with normal cells. Hypoxia increased proliferation in $\mathrm{KC}-\mathrm{KCF}$, but not in normal controls. Data were presented as mean \pm SEM of 8 independent experiments. Significant differences are indicated

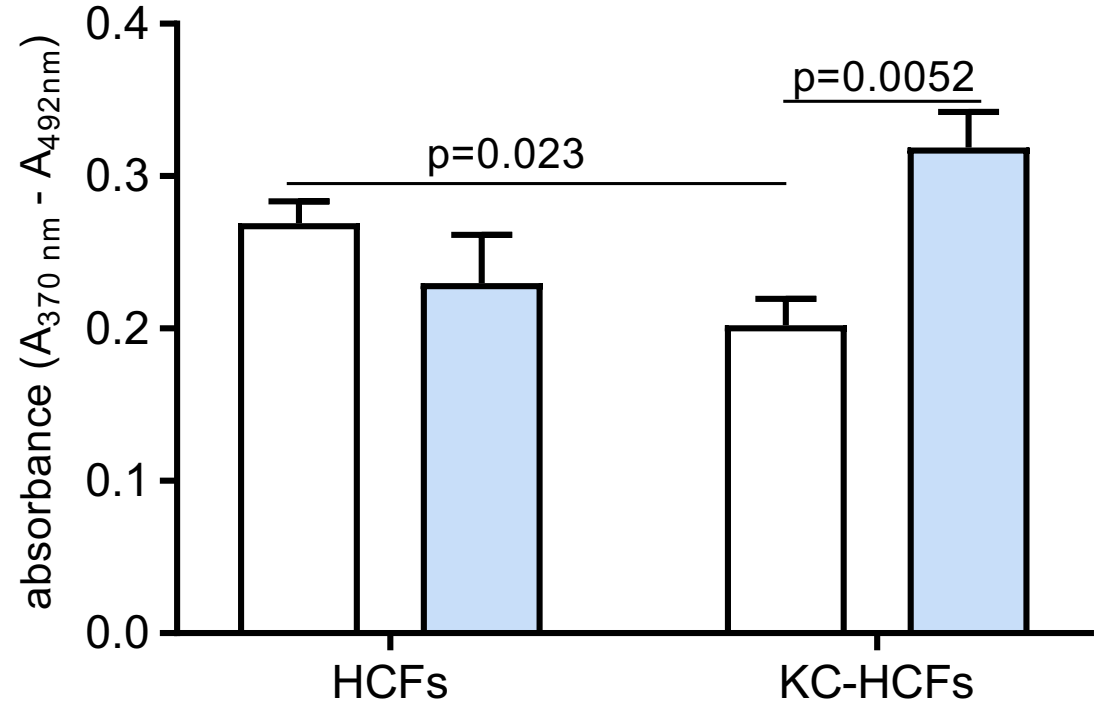


been described. These include genetic, metabolic, and hormonal changes that are correlated with the disease [2, 14-18]. Some of these changes can be associated with increased ROS production in corneal fibroblasts of KC patients $[3,5]$.

$\mathrm{KC}$ is traditionally classified as a non-inflammatory corneal disease. However, in recent years, numerous study groups have demonstrated elevated pro-inflammatory cytokine concentrations in tear fluid of KC patients [19-23]. An inflammatory response is often associated with hypoxia and altered oxidative stress levels [6]. In our previous study, we described that the expression of iNOS mRNA in KC keratocytes is increased compared with normal cells [7], but without a detectable change in the iNOS protein. Normally, iNOS is expressed under inflammatory conditions via the NF- $\mathrm{kB}$ activation mechanism to produce more $\mathrm{NO}$ for the immune response [24]. However, there are also some cell types that permanently express iNOS. The function of constitutively expressed iNOS is not yet fully understood.

In this study, we investigated NF-kB, iNOS, HIF- $1 \alpha$, and HIF- $2 \alpha$ as well as PHD2 expression, ROS production, and proliferation rate under hypoxic conditions in keratoconus corneal fibroblasts in vitro. Our study describes the altered regulation of KC-HCFs, compared with normal HCFs under hypoxic conditions. As the study was performed in cell culture cells, the growth and incubation conditions for the cells were optimal. Therefore, limitation of our study is that a comparison with "in vivo" is difficult.

Our results showed that the regulation of these parameters under hypoxic conditions is altered in $\mathrm{KC}-\mathrm{HCFs}$ compared with normal corneal fibroblasts. NF- $\mathrm{kB}$ and iNOS mRNA expression is increased in KC-HCFs compared with HCFs. After induction of a hypoxic environment, NF- $\mathrm{kB}$ and iNOS mRNA expression is increased in HCFs but not in KC-HCFs. One could speculate that KC-HCFs do not have more capacity to increase NF- $\mathrm{KB}$ and iNOS expression.

It might also be possible that $\mathrm{KC}-\mathrm{HCF}$ counteract a higher expression of NF- $\mathrm{KB}$ and iNOS to avoid an even higher mRNA concentration of iNOS.

The hypoxia-inducible factor (HIF) is a key regulator of oxygen consumption and responsible for the induction of several genes. Under hypoxic conditions, HIF is stabilized by prolyl-hydroxylases (PHDs). The HIF- $\alpha$ translocates into the nucleus and binds to the HIF- $\beta$ unit and serves as a transcription factor for several genes, e.g., for iNOS.

It is quite common to use different times of hypoxic exposure to simulate acute, prolonged, or even chronic hypoxia [25].

Acute hypoxia $(4 \mathrm{~h})$ may have a different effect on the activation of HIF, NF-kB, and iNOS than continuous (24 h) or chronic ( $48 \mathrm{~h}$ ) hypoxic induction. Therefore, we chose different hypoxic exposure times, in order to detect a possible difference between responses of normal and $\mathrm{KC}$ cells. The
HIF- $1 \alpha$ and HIF- $2 \alpha$ subunits are similar in function, but are expressed differently in different tissues. Although the experiments did not show differences in HIF- $1 \alpha$ and HIF- $2 \alpha$ mRNA and protein expression in $\mathrm{KC}$ and normal HCFs, as half-life time of HIF proteins is still extremely short (4-6 min) under hypoxia, we could also have missed the presence of the HIF proteins during our measurement series [26]. Likewise, the expression of HIF- $1 \alpha$ and HIF- $2 \alpha$ seems to be regulated in the same way in normal and KC-HCFs.

The explanation could be that the iNOS regulation is not triggered by HIF, but is regulated directly by NF-KB. The homodimer NF-kp65 (which was measured in our present study as mRNA and protein) can bind directly to the iNOS gene promoter to regulate iNOS expression in myeloid cells [27], and a similar regulatory mechanism might exist in keratoconus cells (Fig. 1). This theory is supported by the fact that PHD2 mRNA and protein expression is similar in HCFs and KC-HCFs after $48 \mathrm{~h}$, although $44 \mathrm{~h}$ earlier, PHD2 mRNA is still in increased in normal HCFs and decreased in KC-HCFs (after $4 \mathrm{~h}$ ). This behavior may be explained by the metabolic dysfunction due to oxidative stress in $\mathrm{KC}$ cells.

It is known that the ROS level of keratoconus cells is higher than in healthy cells. Our studies are consistent with the experiments of Chwa et al., who also reported higher ROS activity of KC-HCFs compared with normal controls [5]. However, there are no studies on the effect of hypoxia on ROS production in corneal fibroblasts. In our experiments, we could show that ROS concentration was lower in HCFs and KC-HCFs after induction of a hypoxic environment.

Hypoxia in glioma cells has been shown to increase the production of free radicals, notably ROS [28]. While cellular responses to hypoxia have been studied extensively, it remains controversial, whether ROS levels increase or decrease at low $\mathrm{O}_{2}$, depending on cell type [29].

In our case, corneal fibroblasts behaved similar to dermal fibroblasts, with a decrease of ROS concentration following hypoxia [29].

Oxidative stress may also regulate the proliferation rate of some cells. The proliferation rate of KC-HCFs was reduced compared with normal cells. Since several proteins like adaptor-related protein complex 2 (AP2B1) and immunoglobulin Lambda-like polypeptide 1(IGLL1), cell division cycle, and apoptosis regulator 1 (CCAR1) are altered in KC, there may be an altered proliferation and apoptosis-related program of these cells [30]. Our experiments show that the proliferation rate after hypoxia increases only in $\mathrm{KC}-\mathrm{HCFs}$, but not in normal control cells. It could be a counter-regulation to increase the proliferation of cells, since in keratoconus there is a reduced cell density in the stroma. Nevertheless, future studies have to clarify the exact proliferation-related alterations in KC-HCFs. 
Many of the known cell physiological changes in keratoconus can be associated with inflammation, oxidative stress, and hypoxia. Our experiments suggest that the response of normal and $\mathrm{KC}$ human fibroblasts to a hypoxic environment may differ to some extent.

\section{Conclusion}

In summary, a hypoxic environment increases NF- $\mathrm{KB}$ and iNOS mRNA expression in normal HCFs but not in KCHCFs. It is possible that the already existing oxidative stress in $\mathrm{KC}$ cells leads to an altered regulation of these parameters, or that the cells no longer have the capacity to further increase NF- $\mathrm{kB}$ and iNOS mRNA due to the metabolic changes.

$\mathrm{NF}-\mathrm{KB}$ regulation is different in normal and $\mathrm{KC}$ cells; it can be speculated that $\mathrm{KC}$ cells need longer time to normalize the NF-kB protein following hypoxia, due to the elevated stress level of these cells.

HIF and PHD2 show no altered iNOS regulation under hypoxic conditions in KC-HCFs and normal HCF, so they do not seem to play a role in keratoconus pathogenesis.

Increased cell proliferation may indicate compensatory mechanisms under hypoxia in $\mathrm{KC}$.

Further studies should investigate the trigger mechanism of $\mathrm{NF}-\mathrm{KB}$ and the binding of the homodimer NF- $\mathrm{KB}$ p 65 to the iNOS promoter of corneal fibroblasts.

The relationship of an inflammatory component to oxidative stress should be further investigated, to better understand the pathogenesis of the disease.

Acknowledgments We would like to thank Prof. Dr. Veit Flockerzi (Department of Experimental and Clinical Pharmacology, Institute of Experimental and Clinical Pharmacology and Toxicology, Center for Molecular Signaling (PZMS), Saarland University, Homburg, Germany) for the use of the Western blot visualization. We thank Prof. Dr. Martin Oberringer (,Department of Trauma-, Hand- and Reconstructive Surgery, Saarland University, Homburg, Germany) for the provision of the hypoxic chamber. The work of Dr. Latta and Dr. Szentmáry at the Rolf M. Schwiete Center for Limbal Stem Cell and Aniridia Research was supported by the Rolf M. Schwiete Foundation.

Authors' contribution TS drafted the manuscript, performed the literature review, and conducted the experiments. LL participated in information gathering and editing. BS proofread the manuscript. NS participated in information and managed the ethical approvement. All authors read and approved the final manuscript.

Funding Open Access funding provided by Projekt DEAL.

Data availability The data used to support the findings of this study are available from the corresponding author upon request.

\section{Compliance with ethical standards}

Competing interests The authors declare that they have no competing interests.

Ethics approval and consent to participate This study was performed in accordance with the Declaration of Helsinki and approved by the Ethics Committee of Saarland/Germany (No. 263/15) and informed consent was obtained from all participants with $\mathrm{KC}$, before keratoplasty was performed.

Abbreviations $\mathrm{KC}$, keratoconus; iNOS, inducible nitric oxide synthase; HIF, hypoxia-inducible factor; PHD2, hypoxia-inducible factor prolylhydroxylase 2; ROS, reactive oxygen species; HCF, human corneal fibroblast; $\mathrm{KC}-\mathrm{HCF}$, keratoconus human corneal fibroblast; NF- $\mathrm{kB}$, nuclear factor kappa B; IL-1, interleukin-1; TNF- $\alpha$, tumor necrosis factor alpha; IFN- $\gamma$, interferon gamma; LPS, lipopolysaccharide; $\mathrm{CoCl} 2$, cobalt chloride

Open Access This article is licensed under a Creative Commons Attribution 4.0 International License, which permits use, sharing, adaptation, distribution and reproduction in any medium or format, as long as you give appropriate credit to the original author(s) and the source, provide a link to the Creative Commons licence, and indicate if changes were made. The images or other third party material in this article are included in the article's Creative Commons licence, unless indicated otherwise in a credit line to the material. If material is not included in the article's Creative Commons licence and your intended use is not permitted by statutory regulation or exceeds the permitted use, you will need to obtain permission directly from the copyright holder. To view a copy of this licence, visit http://creativecommons.org/licenses/by/4.0/.

\section{References}

1. Nishtala K, Pahuja N, Shetty R et al (2016) Tear biomarkers for keratoconus. Eye Vis 3:19. https://doi.org/10.1186/s40662-0160051-9

2. Khaled ML, Helwa I, Drewry M et al (2017) Molecular and histopathological changes associated with keratoconus. Biomed Res Int 2017:1-16. https://doi.org/10.1155/2017/7803029

3. Karamichos D, Hutcheon AEK, Rich CB et al (2014) In vitro model suggests oxidative stress involved in keratoconus disease. Sci Rep 4:4608. https://doi.org/10.1038/srep04608

4. McKay TB, Hjortdal J, Priyadarsini S, Karamichos D (2017) Acute hypoxia influences collagen and matrix metalloproteinase expression by human keratoconus cells in vitro. PLoS One 12:1-13. https://doi.org/10.1371/journal.pone.0176017

5. Chwa M, Atilano SR, Reddy V et al (2006) Increased stressinduced generation of reactive oxygen species and apoptosis in human keratoconus fibroblasts. Invest Ophthalmol Vis Sci 47: 1902-1910. https://doi.org/10.1167/iovs.05-0828

6. McGarry T, Biniecka M, Veale DJ, Fearon U (2018) Hypoxia, oxidative stress and inflammation. Free Radic Biol Med 125:1524. https://doi.org/10.1016/j.freeradbiomed.2018.03.042

7. Stachon T, Latta L, Kolev K, et al (2019) Erhöhte NF-kB und iNOS Expression in Keratozyten von Keratokonus-Patienten - Hinweise auf eine entzündliche Komponente? Klin Monatsbl Augenheilkd [Epup ahea: . https://doi.org/10.1055/a-1002-0100 
8. Bronte V, Zanovello P (2005) Regulation of immune responses by L-arginine metabolism. Nat Rev Immunol 5:641-654. https:/doi. org/10.1038/nri1668

9. Semenza GL (2011) Oxygen sensing, homeostasis, and disease. N Engl J Med 365:537-547. https://doi.org/10.1056/ NEJMra1011165

10. Niederer RL, Perumal D, Sherwin T, McGhee CNJ (2008) Laser scanning in vivo confocal microscopy reveals reduced innervation and reduction in cell density in all layers of the keratoconic cornea. Invest Ophthalmol Vis Sci 49:2964-2970. https://doi.org/10.1167/ iovs.07-0968

11. Senavirathna LK, Huang C, Yang X et al (2018) Hypoxia induces pulmonary fibroblast proliferation through NFAT signaling. Sci Rep 8:2709. https://doi.org/10.1038/s41598-018-21073-x

12. Fini ME (1999) Keratocyte and fibroblast phenotypes in the repairing cornea. Prog Retin Eye Res 18:529-551

13. Ishiuchi N, Nakashima A, Doi S et al (2020) Hypoxiapreconditioned mesenchymal stem cells prevent renal fibrosis and inflammation in ischemia-reperfusion rats. Stem Cell Res Ther 11: 130. https://doi.org/10.1186/s13287-020-01642-6

14. Khaled ML, Bykhovskaya Y, Yablonski SER et al (2018) Differential expression of coding and long noncoding RNAs in keratoconus-affected corneas. Invest Ophthalmol Vis Sci 59: 2717-2728. https://doi.org/10.1167/iovs.18-24267

15. You J, Corley SM, Wen L et al (2018) RNA-Seq analysis and comparison of corneal epithelium in keratoconus and myopia patients. Sci Rep 8:389. https://doi.org/10.1038/s41598-017-18480-x

16. Karamichos D, Zieske JD, Sejersen $\mathrm{H}$ et al (2015) Tear metabolite changes in keratoconus. Exp Eye Res 132:1-8. https://doi.org/10. 1016/j.exer.2015.01.007

17. Sharif R, Bak-Nielsen S, Hjortdal J, Karamichos D (2018) Pathogenesis of Keratoconus: the intriguing therapeutic potential of Prolactin-inducible protein. Prog Retin Eye Res 67:150-167. https://doi.org/10.1016/j.preteyeres.2018.05.002

18. Thanos S, Oellers P, Meyer Zu Horste M et al (2016) Role of thyroxine in the development of keratoconus. Cornea 35:13381346. https://doi.org/10.1097/ICO.0000000000000988

19. Balasubramanian SA, Mohan S, Pye DC, Willcox MDP (2012) Proteases, proteolysis and inflammatory molecules in the tears of people with keratoconus. Acta Ophthalmol 90:e303-e309. https:// doi.org/10.1111/j.1755-3768.2011.02369.x
20. Lema I, Duran JA (2005) Inflammatory molecules in the tears of patients with keratoconus. Ophthalmology 112:654-659. https:// doi.org/10.1016/j.ophtha.2004.11.050

21. Jun AS, Cope L, Speck C et al (2011) Subnormal cytokine profile in the tear fluid of keratoconus patients. PLoS One 6:e16437. https:// doi.org/10.1371/journal.pone.0016437

22. Ionescu IC, Corbu CG, Tanase C et al (2018) Overexpression of tear inflammatory cytokines as additional finding in keratoconus patients and their first degree family members. Mediat Inflamm 2018:4285268. https://doi.org/10.1155/2018/4285268

23. Shetty R, Deshmukh R, Ghosh A et al (2017) Altered tear inflammatory profile in Indian keratoconus patients - the $2015 \mathrm{Col}$ Rangachari Award paper. Indian J Ophthalmol 65:1105-1108. https://doi.org/10.4103/ijo.IJO_233_17

24. Donnelly LE, Barnes PJ (2002) Expression and regulation of inducible nitric oxide synthase from human primary airway epithelial cells. Am J Respir Cell Mol Biol 26:144-151. https://doi.org/10. 1165/ajrcmb.26.1.4477

25. Müller-Edenborn K, Léger K, Glaus Garzon JF et al (2015) Hypoxia attenuates the proinflammatory response in colon cancer cells by regulating IKB. Oncotarget 6:20288-20301. https://doi. org/10.18632/oncotarget.3961

26. Moroz E, Carlin S, Dyomina K et al (2009) Real-time imaging of HIF-1alpha stabilization and degradation. PLoS One 4:e5077. https://doi.org/10.1371/journal.pone.0005077

27. Simon PS, Sharman SK, Lu C et al (2015) The NF-kappaB p65 and p50 homodimer cooperate with IRF8 to activate iNOS transcription. BMC Cancer 15:770. https://doi.org/10.1186/s12885-0151808-6

28. Ogunrinu TA, Sontheimer H (2010) Hypoxia increases the dependence of glioma cells on glutathione. J Biol Chem 285:3771637724. https://doi.org/10.1074/jbc.M110.161190

29. Sgarbi G, Gorini G, Costanzini A et al (2017) Hypoxia decreases ROS level in human fibroblasts. Int J Biochem Cell Biol 88:133144. https://doi.org/10.1016/j.biocel.2017.05.005

30. Soiberman U, Foster JW, Jun AS, Chakravarti S (2017) Pathophysiology of keratoconus: what do we know today. Open Ophthalmol J 11:252-261. https://doi.org/10.2174/ 1874364101711010252

Publisher's note Springer Nature remains neutral with regard to jurisdictional claims in published maps and institutional affiliations. 